\title{
Imiquimod cream efficacy in the treatment of periocular nodular basal cell carcinoma: a non-randomized trial
}

Erick Marcet Santiago de Macedo ${ }^{1}$, Rachel Camargo Carneiro ${ }^{1}$, Patricia Picciarelli de Lima², Breno Gonçalves Silva ${ }^{1}$ and Suzana Matayoshi ${ }^{1^{*}}$

\begin{abstract}
Background: The recurrence rate of periocular nodular basal cell carcinoma (PNBCC) following treatment with imiquimod (IMQ) has not yet been established. Previous studies did not include histological follow-up. The aim of this analysis was to evaluate the efficacy of topical immunotherapy with 5\% IMQ cream for the treatment of PNBCC.

Methods: Study design: A prospective, non-randomized, and uncontrolled longitudinal case series study. No participants were blinded. Punch biopsy confirmed PNBCC patients were included the Ophthalmology Clinic of São Paulo University Medicine School Hospital (from 2008 to 2012). Patients were treated with 5\% IMQ cream once a day, 5 days per week, for 8-16 weeks. Standard lesion photographic documentation was done during the study. Three months after treatment ended, an image-guided biopsy was performed. Patients were followed at 6-month intervals and annually for control biopsies. Main outcome measures were clinical and histological clearance rates. Data were analysed by frequency distribution for qualitative group characteristics and central tendency measures for quantitative data.

Results: Twenty-four patients met the inclusion criteria, 19 of whom remained until the end of treatment. The histological clearance rate was $89.5 \%$ and $84.2 \%$, respectively, at 3 and 39.5 months. The 3 -year histological clearance rate was $81.8 \%(9 / 11)$ for lesions $>10 \mathrm{~mm}$, and $100 \%(8 / 8)$ for lesions $<10 \mathrm{~mm}$. Three patients did not tolerate the side effects of the medication and left the study. Two patients were excluded for treatment interruption related to comorbidities.
\end{abstract}

Conclusions: Our results indicated that 5\% IMQ cream was a useful alternative treatment for NBBCC, especially for lesions $<10 \mathrm{~mm}$. IMQ also showed a significant neoadjuvant effect on lesions $>10 \mathrm{~mm}$.

Trial registration: ClinicalTrial.gov Registration Dec 3, 2008: \#NCT 00803907.

Keywords: Basal cell carcinoma, Periocular neoplasm/therapy, Antineoplastic drug, Immunotherapy, Topical administration

\section{Background}

The incidence of basal cell carcinoma (BCC), the most common human neoplasm, has increased significantly worldwide over the past few years [1,2]. More than $80 \%$ of BCCs affected the neck and face, $20 \%$ of which were in the form of periocular tumours [3]. It was estimated that

\footnotetext{
* Correspondence: suzana.matayoshi@gmail.com

${ }^{1}$ Departments of Ophthalmology and Pathology, University of São Paulo

School of Medicine, Av. Dr. Arnaldo, 455 São Paulo, Brazil

Full list of author information is available at the end of the article
}

$30-40 \%$ of patients with BCC would develop one or more new lesions over the next 10 years [4].

$\mathrm{BCC}$ is the main cause of required reconstructive surgery in the periocular region. For facial BCC, Mohs surgery is considered the method with the best chance of cure, with 5-year recurrence rates of up to 6.5\% [5]. Nodular BCC, the most common subtype in eyelids, has a surgical cure rate of $85-95 \%$ [6].

For cases in which surgery is not possible (multiple lesions, high surgical risk, and refusal of surgery), topical immunotherapy may be an alternative. Imiquimod (IMQ), an 
immune modulator, acts by stimulating innate and adaptive immunity and by inducing apoptosis in tumour cells [2]. The ideal mode of administration of IMQ remains uncertain. The drug has been applied once or twice per day or 3-7 times a week during 6-16 weeks with variable results $[7,8]$.

IMQ use, as an alternative treatment for periocular BCC, was suggested using results from a small case series with an almost 100\% reported cure rate [9-11]. However, no histological follow-up was provided in these studies. Leppala et al. [12] and Garcia-Martin et al. [13], however, demonstrated short-term (3 months) biopsy documentation after treatments. For periocular NBCC (PNBCC), Eigentler et al. showed residual tumours in one third of patients given IMQ three times per week for 8-12 weeks [8].

The purpose of the present study was therefore to evaluate clinically and histologically the effects of $5 \%$ topical IMQ cream on PNBCC by evaluating for residual tumour rate and recurrence.

\section{Methods}

This was an interventional prospective, non-randomized, and uncontrolled longitudinal case series study, conducted between 2008 and 2012. The study followed the tenets of the Declaration of Helsinki, and was approved by the University of São Paulo Medical School Hospital Institutional Review Board Ethics Committee. All participants gave their informed consent. The ClinicalTrial.gov number was NCT00803907.

Patients with periocular biopsy diagnosed as NBCC were included in this study. We limited eyelid margin lesions up to $20 \mathrm{~mm}$, and medial canthus lesions up to $30 \mathrm{~mm}$ (largest diameter), with no infiltrating deeper tissues on palpation. All lesions had not had prior treatment. Recurrent $\mathrm{BCC}$ lesions and patients with clinical signs of orbit invasion were excluded. Uncooperative patients with no caregiver assistance to correctly apply the medication were also excluded.

Main outcome measures were clinical and histological clearance rates. To detect a histological tumour clearance rate of $50 \%$ at 3 months, with a 5\% significance level and $95 \%$ confidence, a sample size of 22 patients was necessary, given an anticipated dropout rate of 10\% (http://www.nss. gov.au/nss/home.nsf/). All patients were submitted to IMQ cream treatment. No participants were blinded.

IMQ cream (Aldara ${ }^{\circ}$; Meda AB, Graceway Pharmaceuticals, Bristol, TN, USA) was applied once each day at bedtime. To ensure patient safety, we instructed patients and caregivers (or relatives) to use lubricating gel in the conjunctival sac before IMQ cream application. We stressed the correct medication application, using a swab, and taking care to keep the border of the eyelid away from the eye. The cream remained in contact with the tumour for 8 to 10 hours. In the morning, the periocular area was washed with neutral liquid soap. In cases of accidental contact with the ocular surface and conjunctiva, the patient was instructed to wash abundantly with saline solution and apply lubricating eye gel.

Artificial tears were prescribed and provided free of charge to the patients, for application every 6 hours during the day. IMQ was used once each day, 5 days a week, for a minimum of 8 weeks and a maximum of 16 weeks. Within this period, treatment was discontinued once the lesion became undetectable by slit lamp examination and palpation.

During the treatment period, patients were followed biweekly and information was collected through questionnaires, slit lamp examinations, visual acuity testing, photography, and measurement of lesions, using Image J software (version 1.42) [14].

Baseline measurements were obtained from photographs taken after the initial biopsy so that the amount of tissue removed would not influence the results. The final measurements were based on photographs taken 3 months (12 weeks) after treatment end.

We used 2-mm trephine for all biopsies. An imageguided biopsy of the region was performed 3 months (12 weeks) after treatment. Patients with clinical or histological findings of residual lesions were referred for surgical excision and reconstruction. Patients were followed at 6-month intervals, with annual control biopsies.

Data were analysed by frequency distribution for qualitative group characteristics and central tendency measures for quantitative data.

\section{Results}

Throughout the study, 24 patients met the inclusion criteria, 19 of whom remained until the end of treatment. Patients were recruited until December 2012 when the required sample size was obtained. Three patients did not tolerate the side effects of the medication and left the study. One patient suffered an ischemic cerebrovascular accident, and one patient died during the treatment period. Both cases were associated with previous diseases and high surgical risk (Figure 1).

One patient (case 12) interrupted treatment for 2 weeks because of intense local inflammation associated with systemic symptoms. This patient was also the only patient who experienced tumour recurrence, as confirmed by biopsy 2 years after treatment (Figure 2).

Seventeen patients had complete clinical clearance at the 3-month evaluation (Table 1). Two patients had a residual tumour (Table 2). Punch biopsy showed a histologically tumour-free rate of $89.5 \%$ at 3 months and $84.2 \%$ by the end of follow-up (39.5 months) (Table 1 ). Two cases with successful outcomes are shown in Figure 3. 

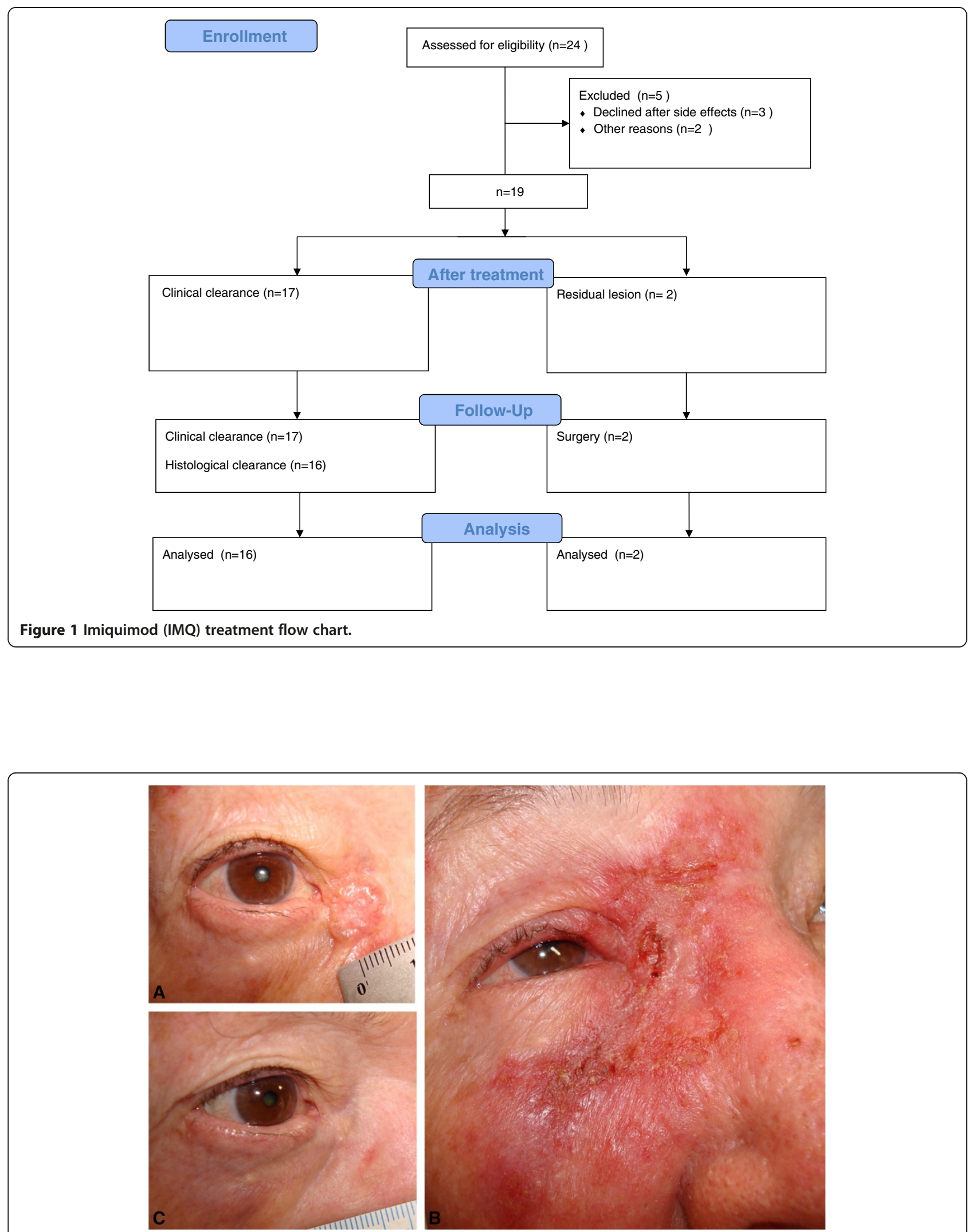

Figure 2 Lesion \#12. Nodular basal cell carcinoma in the medial canthus. A) before treatment, B) local inflammation mimicking preseptal cellulitis, C) 2 years after treatment completion, when the biopsy identified BCC recurrence. 
Table 1 Description of the lesions treated with $5 \%$ imiquimod cream

\begin{tabular}{lll}
\hline Variable & Frequency & $\%$ \\
\hline Age (years) & 5 & 26.3 \\
$<60$ & 9 & 47.4 \\
$60-70$ & 5 & 26.3 \\
$>70$ & & \\
Gender & 13 & 68.4 \\
Male & 6 & 31.6 \\
Female & & \\
Tumour site & 8 & 42.1 \\
Lower eyelid & 11 & 57.9 \\
Medial canthus & & \\
Fitzpatrick scale & 13 & 68.3 \\
2 & 4 & 21.1 \\
3 & 1 & 5.3 \\
4 & 1 & 5.3 \\
5 & & \\
Clinical cure at 3 months & 19 & 10.8 \\
Yes & 2 & 10.5 \\
No & & \\
Histological cure at 3 years & 16.5 \\
Yes & & \\
No & & \\
Total & & \\
\hline & & \\
\hline & & \\
\hline
\end{tabular}

The most frequent ocular symptoms and signs were conjunctivitis (95\%), followed by keratitis (84\%), foreign body sensation (79\%), lacrimation (58\%), low visual acuity (53\%), and ectropion (37\%). Treatment consisted of frequent lubrication with eye drops. All patients presented with some degree of skin reaction such as hyperaemia, crusting, ulceration, and bleeding during treatment. No medication was prescribed except for cold compresses. No side effects were permanent and all were resolved after the end of treatment.

\section{Discussion}

The current investigation confirmed several previous studies reporting favourable results with IMQ $[12,13]$ and suggested that IMQ played an important role in the management of PNBCC as an alternative non-surgical treatment. The present study proposed treatment once per day, five times per week for 8 to 16 weeks. Treatment time depended on healing of skin and absence of tumours at slit lamp examination, and on palpation, therefore treatment lasted 12.6 weeks on average. Histological clearance was $89.5 \%(17 / 19)$ by the end of the treatment, and $84.2 \%$ $(16 / 19)$ after 3 years of follow-up (Table 2).
Previous PNBCC studies reported treatments lasting 6 weeks, at seven applications per week and with $71 \%$ efficacy, and 50-59\% efficacy with three applications $[15,16]$. However, three applications per week for 8 weeks yielded an efficacy of $64 \%$ [8]. The highest cure rates reported were observed with treatment for 12 weeks as follows: 60-63\% efficacy with three applications per week, $70 \%$ efficacy with five applications per week, and 76\% efficacy with seven applications per week $[8,16]$.

In the present study, $57.9 \%(11 / 19)$ of the patients had lesions $>10 \mathrm{~mm}$. Interestingly, the 3 -year histological clearance rate was $81.8 \%(9 / 11)$ for lesions $>10 \mathrm{~mm}$, and $100 \%(8 / 8)$ for lesions $<10 \mathrm{~mm}$. Eigentler et al. obtained the best results in smaller lesions $(72 \%$ cure rate for smaller lesions versus $48 \%$ for larger lesions), and observed that the larger the tumour, the less efficacious the medication and the longer the required treatment [8].

Thus, a treatment duration of 6 weeks was reported to be a negative prognostic factor in the treatment of periocular lesions larger than $10 \mathrm{~mm}$ [13]. This finding was supported by the association between tumour profile (percentage of tumours greater than $10 \mathrm{~mm}$ and mean and median lesion size) and different dosage regimens used in six studies evaluating treatment of PNBCC with 5\% IMQ cream (Table 3) [9-13,17]. Partial resolution (tumours were reduced but did not disappear completely, producing a neoadjuvant effect) was more commonly observed with nodular lesions when compared with superficial BCC [18].

Only two of our patients had partial tumour clearance. Both had lesions larger than $10 \mathrm{~mm}$, and in both cases the medication had a neoadjuvant effect, significantly reducing tumour size and thereby facilitating surgery (Table 1). The less healthy the tissue removed in surgery, the smaller the risk of compromising eyelid function and aesthetics. The main complications of surgical excision of large amounts of periocular tissue included scarring, palpebral retraction, trichiasis, ptosis, chronic epiphora, entropion, ectropion, keratitis, and corneal ulcer caused by exposure or perforation [19].

At baseline, lesion 1 (lower eyelid margin) measured $13.5 \mathrm{~mm}$. Adding a 2-mm safety margin on each side, an area equivalent to half the eyelid $(17.5 \mathrm{~mm})$, would have required reconstruction of the eyelid. After treatment with 5\% IMQ cream, the diameter was reduced to $4.2 \mathrm{~mm}$. Including the safety margin, the area to be reconstructed $(8.2 \mathrm{~mm})$ was less than one third the size of the eyelid. In this patient the safety margins were free and the lesion was submitted to pentagonal excision, cantholysis, and closure.

Lesion 8 (medial canthus) was reduced from $27.2 \mathrm{~mm}$ to $7.6 \mathrm{~mm}$. Thus, instead of performing a complex surgery with glabellar flap rotation and advancement, the patient was submitted to simple excision and direct closure of the tumour-free surgical margins. 
Table 2 Description of 19 patients with confirmed periocular basal cell carcinoma treated with $\mathbf{5 \%}$ imiquimod cream

\begin{tabular}{|c|c|c|c|c|c|}
\hline Lesion & ${ }^{\dagger}$ Area $\left(\mathrm{mm}^{2}\right)$ & ${ }^{\dagger}$ Largest diameter $(\mathrm{mm})$ & ${ }^{\ddagger}$ Residual area $\left(\mathrm{mm}^{2}\right)$ & ${ }^{\ddagger}$ Largest residual diameter $(\mathrm{mm})$ & Treatment time (weeks) \\
\hline 1 & 131.97 & 12.01 & 13.53 & 4.25 & 8 \\
\hline 2 & 108.18 & 11.70 & 0 & 0 & 12 \\
\hline 3 & 64.56 & 10.63 & 0 & 0 & 16 \\
\hline 4 & 67.09 & 11.65 & 0 & 0 & 12 \\
\hline 5 & 53.34 & 15.03 & 0 & 0 & 12 \\
\hline 6 & 20.76 & 5.10 & 0 & 0 & 8 \\
\hline 7 & 32.32 & 7.51 & 0 & 0 & 10 \\
\hline 8 & 165.38 & 27.18 & 22.07 & 7.63 & 12 \\
\hline 9 & 189.14 & 17.96 & 0 & 0 & 12 \\
\hline 10 & 18.53 & 5.06 & 0 & 0 & 14 \\
\hline 11 & 15.99 & 2.77 & 0 & 0 & 12 \\
\hline 12 & 121.01 & 15.66 & 0 & 0 & 16 \\
\hline 13 & 35.53 & 9.46 & 0 & 0 & 14 \\
\hline 14 & 45.32 & 16.01 & 0 & 0 & 12 \\
\hline 15 & 4.36 & 2.82 & 0 & 0 & 12 \\
\hline 16 & 39.83 & 10.29 & 0 & 0 & 14 \\
\hline 17 & 121.27 & 15.45 & 0 & 0 & 16 \\
\hline 18 & 60.63 & 8.70 & 0 & 0 & 16 \\
\hline 19 & 32.18 & 5.38 & 0 & 0 & 12 \\
\hline
\end{tabular}

${ }^{\dagger}$ Before treatment, ${ }^{\ddagger} 3$ months after treatment completion.

The patient with lesion 12 interrupted the treatment for 2 weeks because of intense local inflammation mimicking preseptal cellulitis, but systemic symptoms were also observed, especially diarrhoea. The interruption may have influenced the evolution because this was the only patient with recurrence of BCC (Figure 1). There was evidence that recurrence of superficial BCC was low after treatment with IMQ and that the resolution rate remained high during 5 years of clinical follow-up. The clinical and histological outcome 12 weeks after treatment appeared to be a reliable predictor of the risk of recurrence, which was most commonly observed during the first year of follow-up [20].

Bath-Hextall et al. recently reported a large randomized trial with 3 years of follow-up comparing IMQ and surgery in nodular and superficial BCC, showing a recurrence rate of $18.3 \%$. However, this study did not include periocular regions [21]. The recurrence rate of PNBCC following treatment with IMQ has not yet been established. Studies with a larger series of BCC patients have focused on short-term elimination of tumours rather than on the observation of recurrence. We identified only one study with a long enough follow-up time to detect recurrence, a study of four patients with BCC in the periocular area, followed up for 7 years [11]. Two studies performed biopsy at 3 months [12,13]. Because PNBCC is more complex and more established than superficial BCC, late recurrence without clinical signs is a possibility, and was observed for lesion 12 (Figure 1-C), which recurred after 2 years.

Our study was the largest IMQ-treated PNBCC patient series with histological follow-up beyond 3 years. Follow-up for recurrence was based on clinical examinations and histological controls. Excisional biopsy of whole compromised areas would be desirable but not feasible to perform every year. The 2-mm punch biopsy used here was a swift and simple diagnostic technique with a high level of agreement compared with analysis of whole surgical specimens (90\% accuracy for malignancy diagnosis) [22].

Despite longer treatment, our patients had only minor ocular symptoms (conjunctivitis, keratitis, and foreign body sensation) and no permanent eye damage was observed. Cannon et al., in a retrospective study, described conjunctivitis and eye burning sensation as the most common symptoms during treatment of periocular lesions, despite the fact that only three in a sample of 47 patients had periocular BCC, and IMQ was administered three times per week for 4-6 weeks [23]. All symptoms caused by the medication were transient and resolved after ending treatment.

The main limitation of the present study was the lack of a comparative group (such as a surgical group). Regarding generalization to other cases, our cases consisted of primary PNBCC lesions without signs of deep infiltration or orbit invasion, therefore it was a limited group of patients. 


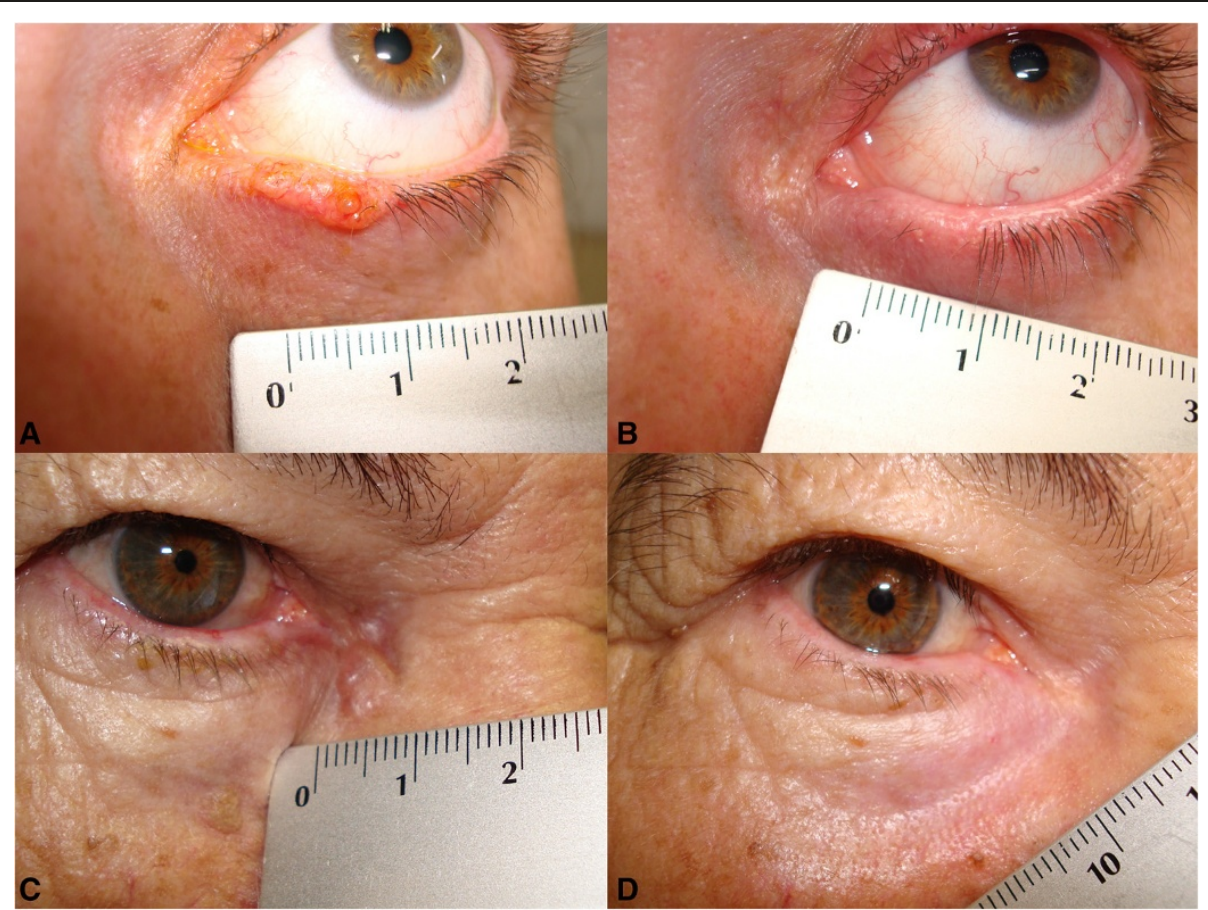

Figure 3 Clinical pictures before and $\mathbf{3}$ years after treatment. A) Case \#13: Eyelid margin PNBCC, B) after treatment, C) case \#4, medial canthus PNBCC, D) after treatment.

Although surgical excision remains the gold standard for PNBCC and is associated with the highest cure rates [24], in the present study IMQ was shown to be an efficacious and safe alternative treatment. However, we stress the importance of careful follow-up even after clinical clearance to manage recurrence cases.

\section{Conclusions}

The recurrence rate of periocular nodular basal cell carcinoma (BCC) following treatment with IMQ was low. The 3-year histological clearance rate was $100 \%$ (8/8) for lesions $<10 \mathrm{~mm}$ and $81.8 \%$ (9/11) for lesions $>10 \mathrm{~mm}$. Importantly, IMQ had significant neoadjuvant effects on PNBCC lesions $>10 \mathrm{~mm}$.

Table 3 Comparison of results evaluating imiquimod treatment of periocular nodular basal cell carcinoma

\begin{tabular}{|c|c|c|c|c|c|c|c|}
\hline First author year & $\mathbf{N}$ & $\begin{array}{l}\text { Dosing regimen, } \\
\text { days/week, weeks }\end{array}$ & $\begin{array}{l}\text { Mean size } \\
\text { (SD) } \mathrm{mm}\end{array}$ & $\begin{array}{l}\text { Lesions greater } \\
\text { than } 10 \mathrm{~mm}(\%)\end{array}$ & $\begin{array}{l}\text { Complete } \\
\text { response (\%) }\end{array}$ & Follow-up (years) & $\begin{array}{l}\text { Histological } \\
\text { follow-up (months) }\end{array}$ \\
\hline \multirow[t]{2}{*}{ Present study } & 19 & $5 /$ wk & $11.1(6.0)$ & 58 & 84.2 & 3.3 & 36 \\
\hline & & $8-16$ wk & & & & & \\
\hline \multirow[t]{2}{*}{ Prokosch 2011 [11] } & 4 & $5 /$ wk & $11.5(4.5)$ & 50 & 100 & 7.0 & - \\
\hline & & $6 w k$ & & & & & \\
\hline \multirow[t]{2}{*}{ Garcia-Martin 2010 [13] } & 15 & $5 /$ wk & $7.6(2.9)$ & 25 & 100 & 2.0 & 3 \\
\hline & & $6 w k$ & & & & & \\
\hline \multirow[t]{2}{*}{ Carneiro 2010 [22] } & 10 & $5 /$ wk & $12.1(6.5)$ & 60 & 80 & 1.0 & 12 \\
\hline & & 10-16 wk & & & & & \\
\hline \multirow[t]{2}{*}{ Choontanom 2007 [10] } & 5 & $5 /$ wk & $10.8(4.2)$ & 40 & 80 & 3.0 & - \\
\hline & & $6 w k$ & & & & & \\
\hline \multirow[t]{2}{*}{ Leppälä 2007 [12] } & 4 & $5 /$ wk & $8.5(4.6)$ & 25 & 100 & 0.5 & 3 \\
\hline & & $6 w k$ & & & & & \\
\hline \multirow[t]{2}{*}{ Blasi 2005 [9] } & 2 & $3 / w k$ & - & - & 100 & 1.0 & - \\
\hline & & $8-12 w k$ & & & & & \\
\hline
\end{tabular}




\section{Competing interests}

The authors declare that they have no competing interests.

\section{Authors' contributions}

EMSM conceived the study, collected and analysed the data, and drafted the manuscript; RCC contributed to data analysis and drafted the manuscript; PP and BS contributed to the study design, data collection, and critically reviewed and revised the manuscript; SM participated in the design of the study, and critically reviewed and revised the manuscript. All authors approved the final version of the manuscript.

\section{Authors' information}

EMSM - Postgraduate ophthalmologist at São Paulo University Medicine School.

RCC - Postgraduate ophthalmologist at São Paulo University Medicine School.

PP - Pathologist specialising in Ophthalmic Pathology at São Paulo University Medicine School.

BS - Ophthalmology resident.

SM - Associate Professor at São Paulo University Medicine School.

\section{Acknowledgements}

We thank the CNPq -Brazilian Council of Research for funding the study.

\section{Author details}

'Departments of Ophthalmology and Pathology, University of São Paulo School of Medicine, Av. Dr. Arnaldo, 455 São Paulo, Brazil. ${ }^{2}$ Departments of Pathology, University of São Paulo School of Medicine, Av. Dr. Arnaldo, 455 São Paulo, Brazil.

Received: 12 May 2014 Accepted: 24 March 2015

Published online: 03 April 2015

\section{References}

1. Crowson AN. Basal cell carcinoma: biology, morphology and clinical implications. Mod Pathol. 2006;19 Suppl 2:S127-147.

2. Collins GL, Nickoonahand N, Morgan MB. Changing demographics and pathology of nonmelanoma skin cancer in the last 30 years. Semin Cutan Med Surg. 2004:23:80-3.

3. Allali J, D'Hermies F, Renard G. Basal cell carcinomas of the eyelids. Ophthalmologica. 2005;219:57-71.

4. McGuire JF, Ge NN, Dyson S. Nonmelanoma skin cancer of the head and neck I: histopathology and clinical behavior. Am J Otolaryngol. 2009;30:121-33.

5. Smith V, Walton S. Treatment of facial Basal cell carcinoma: a review. J Skin Cancer 2011; doi 10.1155_2011_380371

6. Bøgelund FS, Philipsen PA, Gniadecki R. Factors affecting the recurrence rate of basal cell carcinoma. Acta Derm Venereol. 2007:87:330-4.

7. Geisse J, Caro I, Lindholm J, Golitz L, Stampone P, Owens M. Imiquimod 5\% cream for the treatment of superficial basal cell carcinoma: results from two phase III, randomized, vehicle-controlled studies. J Am Acad Dermatol. 2004;50:722-33.

8. Eigentler TK, Kamin A, Weide BM, Breuninger H, Caroli UM, Möhrle M, et al. A phase III, randomized, open label study to evaluate the safety and efficacy of imiquimod 5\% cream applied thrice weekly for 8 and 12 weeks in the treatment of low-risk nodular basal cell carcinoma. J Am Acad Dermatol. 2007:57:616-21.

9. Blasi MA, Giammaria D, Balestrazzi E. Immunotherapy with imiquimod 5\% cream for eyelid nodular basal cell carcinoma. Am J Ophthalmol. 2005;140:1136-9.

10. Choontanom R, Thanos S, Busse H, Stupp T. Treatment of basal cell carcinoma of the eyelids with 5\% topical imiquimod: a 3-year follow-up study. Graefes Arch Clin Exp Ophthalmol. 2007;245:1217-20.

11. Prokosch V, Thanos S, Spaniol K, Stupp T. Long-term outcome after treatment with $5 \%$ topical imiquimod cream in patients with basal cell carcinoma of the eyelids. Graefes Arch Clin Exp Ophthalmol. 2011;249:121-5.

12. Leppala J, Kaarniranta K, Uusitalo H, Kontkanen M. Imiquimod in the treatment of eyelid basal cell carcinoma. Acta Ophthalmol Scand. 2007:85:566-8

13. Garcia-Martin E, Idoipe M, Gil LM, Pueyo V, Alfaro J, Pablo LE, et al. Efficacy and tolerability of imiquimod $5 \%$ cream to treat periocular basal cell carcinomas. J Ocul Pharmacol Ther. 2010;26:373-9.
14. Image J [http://rsbweb.nih.gov/ij/] acessed 12 Oct 2008

15. Sterry W, Ruzicka T, Herrera E, Takwale A, Bichel J, Andres K, et al. Imiquimod 5\% cream for the treatment of superficial and nodular basal cell carcinoma: randomized studies comparing low-frequency dosing with and without occlusion. Br J Dermatol. 2002;147:1227-36.

16. Shumack S, Robinson J, Kossard S, Golitz L, Greenway H, Schroeter A, et al. Efficacy of topical $5 \%$ imiquimod cream for the treatment of nodular basal cell carcinoma: comparison of dosing regimens. Arch Dermatol. 2002;138:1165-71.

17. Carneiro RC, de Macedo EM, Matayoshi S. Imiquimod 5\% cream for the treatment of periocular Basal cell carcinoma. Ophthal Plast Reconstr Surg. 2010;26:100-2.

18. Peris K, Campione E, Micantonio T, Marulli GC, Fargnoli MC, Chimenti S. Imiquimod treatment of superficial and nodular basal cell carcinoma: 12-week open-label trial. Dermatol Surg. 2005;31:318-23.

19. García Martín E, Fernández Tirado FJ. Periocular basal cell carcinoma treatment tendencies. Arch Soc Esp Oftalmol. 2010;85:261-2.

20. Gollnick H, Barona CG, Frank RG, Ruzicka T, Megahed M, Maus J, et al. Recurrence rate of superficial basal cell carcinoma following treatment with imiquimod 5\% cream: conclusion of a 5-year long-term follow-up study in Europe. Eur J Dermatol. 2008;18(6):677-82.

21. Bath-Hextall F, Ozolins M, Armstrong SJ, Colver GB, Perkins W, Miller PS, et al. Surgical excision versus imiquimod $5 \%$ cream for nodular and superficial basal-cell carcinoma (SINS): a multicentre, non-inferiority, randomised controlled trial. Lancet Oncol. 2015;15:96-105.

22. Carneiro RC, de Macedo EM, de Lima PP, Bonatti R, Matayoshi S. Is 2-mm punch biopsy useful in the diagnosis of malignant eyelid tumors? Ophthal Plast Reconstr Surg. 2012;28:282-5.

23. Cannon PS, O'Donnell B, Huilgol SC, Selva D. The ophthalmic side-effects of imiquimod therapy in the management of periocular skin lesions. $\mathrm{Br}$ J Ophthalmol. 2011;95:1682-5.

24. Levin F, Khalil M, McCormick SA, Della Rocca D, Maher E, Della Rocca RC. Excision of periocular basal cell carcinoma with stereoscopic microdissection of surgical margins for frozen-section control: report of 200 cases. Arch Ophthalmol. 2009;127:1011-15.

\section{Submit your next manuscript to BioMed Central and take full advantage of:}

- Convenient online submission

- Thorough peer review

- No space constraints or color figure charges

- Immediate publication on acceptance

- Inclusion in PubMed, CAS, Scopus and Google Scholar

- Research which is freely available for redistribution 